\title{
Effects of Single a-to- $\beta$ Residue Replacements on Structure and Stability in a Small Protein: Insights from Quasiracemic Crystallization
}

\author{
Dale F. Kreitler ${ }^{\varphi}$, David E. Mortenson ${ }^{\varphi, \dagger}$, Katrina T. Forest ${ }^{\psi},{ }^{*}$, and Samuel H. Gellman ${ }^{\varphi},{ }^{\star}$ \\ Department of Chemistry, University of Wisconsin, Madison, Wisconsin 53706, United States \\ \%Department of Bacteriology, University of Wisconsin, Madison, Wisconsin 53706, United States
}

\begin{abstract}
Synthetic peptides that contain backbone modifications but nevertheless adopt folded structures similar to those of natural polypeptides are of fundamental interest and may provide a basis for biomedical applications. Such molecules can, for example, mimic the ability of natural prototypes to bind to specific target macromolecules but resist degradation by proteases. We have previously shown that oligomers containing mixtures of $\alpha$ - and $\beta$-amino acid residues (" $a / \beta$-peptides") can mimic the $\alpha$-helix secondary structure, and that properly designed $\alpha / \beta$-peptides can bind to proteins that evolved to bind to $\alpha$-helical partners. Here we report fundamental studies that support the long-range goal of extending the $\alpha / \beta$ approach to tertiary structures. We have evaluated the impact of single $\alpha \rightarrow \beta$ modifications on the structure and stability of the small and well-studied villin headpiece subdomain (VHP). The native state of this 35-residue polypeptide contains several $a$-helical segments packed around a small hydrophobic core. We examined $\alpha \rightarrow \beta$ substitution at four solvent-exposed positions, Asn19, Trp23, Gln26 and Lys30. In each case, both the $\beta^{3}$ homologue of the natural $\alpha$ residue and a cyclic $\beta$ residue were evaluated. All $\alpha \rightarrow \beta^{3}$ substitutions caused significant destabilization of the tertiary structure as measured by variable-temperature circular dichroism, although at some of these positions, replacing the $\beta^{3}$ residue with a cyclic $\beta$ residue led to improved stability. Atomic-resolution structures of four VHP analogues were obtained via quasiracemic crystallization. These findings contribute to a fundamental $\alpha / \beta$-peptide knowledge-base by confirming that $\beta^{3}$-amino acid residues can serve as effective structural mimics of homologous $\alpha$-amino acid residues within a natural tertiary fold, which should support rational design of functional $\alpha / \beta$ analogues of natural poly- $\alpha$-peptides.
\end{abstract}

Proteins perform a broad range of functions; most activities depend on the ability of a polypeptide chain to adopt a specific shape and thereby present a particular set of side chains

\footnotetext{
*Corresponding Authors: gellman@chem.wisc.edu, forest@bact.wisc.edu.

$\dagger$ Present Addresses: Scripps Research institute, La Jolla, California, 92037, United States

ASSOCIATED CONTENT

Supporting Information.

Experimental details including peptide synthesis and characterization; thermal denaturation modeling; X-ray diffraction data collection, structure solution, and refinement; additional heterochiral packing interactions; structure factor amplitude statistical analysis. This material is available free of charge via the Internet at http://pubs.acs.org. Model coordinates and structure factors have been deposited in the Protein Data Bank as entries 5I1N ( $\beta^{3}$-hGln26 quasiracemate), 5I1O (ACPC26 quasiracemate), $5 \mathrm{I1O}$ ( $\beta^{3}$ hLys30 quasiracemate), and 5I1S (APC30 quasiracemate).
} 
in a defined three-dimensional arrangement. The wide variation in shape and function among natural proteins is achieved with a backbone that contains exclusively a-amino acid residues. Efforts to develop analogues of natural polypeptides that display altered activities have focused largely on side chain modification, a choice that is based on both synthetic and structural considerations. Efficient ribosomal biosynthesis is limited to sequences that contain primarily L-a-amino acid residues, and solid-phase synthesis, which offers access to greatly enhanced side chain diversity at the cost of diminished chain length, has been heavily optimized for $\mathrm{a}$-amino acid incorporation. The most common protein secondary structures, including $\alpha$-helices, 310 -helices, $\beta$-sheets and $\beta$-turns, depend on specific $\mathrm{H}$-bond patterns involving backbone amides as donors and acceptors; therefore, it might be assumed that altering the covalent connectivity among backbone amide groups, as must occur if a-amino acid residues are replaced with other types of amino acid residues, would disrupt the folding patterns necessary for the functions of natural polypeptides.

This work assesses the impact of replacing a single $a$-amino acid residue with a $\beta$-amino acid residue in the context of the small and well-studied tertiary structure formed by the villin headpiece subdomain (VHP). ${ }^{1-3}$ Each variant containing an $a \rightarrow \beta$ replacement is compared with VHP itself in terms of stability, via thermal denaturation, and in several cases the structures are compared via X-ray crystallography. To place our findings in context, we briefly review the precedents for $\alpha \rightarrow \beta$ replacement within polypeptides and identify knowledge gaps.

Efforts focused on a-helix mimicry by backbone-modified polypeptides have revealed that the structural and informational features of natural a-helices can be recapitulated with oligomers that contain $\alpha$ - and $\beta$-amino acid residues in simple patterns. ${ }^{4-7}$ The secondary structure adopted by these $\alpha / \beta$-peptides is very similar to the canonical $\alpha$-helix despite the presence of 'extra' backbone carbon atoms (Figure 1), although the impact of $a \rightarrow \beta$ replacement on helix stability is not presently clear. Initial studies of a-helix-mimetic a/ $\beta$ peptides were motivated by the hypothesis that such oligomers would maintain the recognition properties of a prototype ahelix but be less susceptible to enzymatic degradation. ${ }^{8}$ This hypothesis has been borne out in several systems in which the recognition of multi-turn $\alpha$-helices by partner proteins can be mimicked with $\alpha / \beta$-peptides containing $25-33 \% \beta$ residues evenly distributed along the sequence. ${ }^{4,9,10}$ An unanticipated outcome of these studies was the discovery that some patterns of $\alpha \rightarrow \beta$ replacement engender unique recognition selectivities among sets of related binding proteins ${ }^{11}$ or even among functionally distinct conformations of a single binding protein. ${ }^{12}$

Systematic evaluation of $a \rightarrow \beta$ replacements in the context of $\beta$-sheet secondary structure have been conducted by Horne et al. ${ }^{13,14}$ This work showed that a two-stranded " $\beta$-hairpin" conformation can be maintained when cross-strand pairs of a residues are replaced with $\beta$ residues; however, such insertions alter the global pattern of side chain display relative to the prototype all-a hairpin. The side chain display can be more effectively maintained if each $\beta$ residue replaces a sequentially adjacent pair of a residues. ${ }^{14}$ Martinek et al. have reported that the anti-angiogenic properties of a designed $\beta$-sheet-forming peptide can be retained after a few $\alpha \rightarrow \beta$ replacements ${ }^{15}$ despite the alterations in side chain positioning that would be predicted based on the findings of Horne et al. ${ }^{13,14}$ 
A long term goal in this field is to understand impacts of $a \rightarrow \beta$ replacements not only on local secondary structure and binding properties but also on tertiary structure and biological function. To date, pioneering exploratory studies have led to variable outcomes; a unifying set of rules governing impacts of such replacements is still needed. Analogues of RNase A in which a two-residue reverse turn was replaced with a di- $\beta$ peptide displayed native-like catalytic function. ${ }^{16}$ Similarly, David et al. described an IL-8 analogue in which the Cterminal $a$-helix was replaced with a geometrically divergent $\beta$-peptide helix; signaling activity, mediated by the N-terminal portion, was retained by this hybrid polypeptide. ${ }^{17}$ However, Denton et al. found that replacing the a-helical C-terminal portion of the hormone GLP-1 with the same sort of $\beta$-peptide helix led to a million-fold loss in activity. ${ }^{10}$ Similarly, experiments involving analogues of parathyroid hormone suggested that even limited and conservative backbone alterations could be highly deleterious to natural function. ${ }^{9,18}$ Thus, strategic substitution of a natural secondary structure element with a backbone-modified segment can be tolerated in some cases, but not all.

Recent reports have extended the periodic $a \rightarrow \beta$ replacement strategy to $a$-helices within model tertiary or quaternary structures. These studies are significant because the results pertain to larger and more irregular surfaces than those presented by a single helix. Horne et al. explored multiple $\alpha \rightarrow \beta$ replacements within the small protein GB1. ${ }^{19,20}$ Crystal structures of several backbone-modified GB1 variants showed that a native-like tertiary structure was retained in each case. Hilvert et al. examined $\alpha \rightarrow \beta$ replacements in an $\alpha-$ helical segment within an engineered two-component chorismate mutase. ${ }^{21}$ This helix contributes a key arginine side chain to the active site. Several $a \rightarrow \beta$ substitution patterns were found to support near-native levels of catalytic activity. Checco et al. developed a/ $\beta$ peptides that adopt a helix-loop-helix tertiary structure and target specific binding surfaces on partner proteins. ${ }^{22}$ Crystallographic characterization of one $a / \beta$ peptide bound to a protein partner (vascular endothelial growth factor) showed that a-helix-like secondary structure was maintained despite the presence of multiple $\beta$ residues.

Collectively, the studies of $\alpha \rightarrow \beta$ replacement summarized above suggest that certain substitutions can result in partial or full retention of a prototype poly-a-peptide's structure and function; however, most of the precedents fail to provide insight on the impact of $\alpha \rightarrow \beta$ replacement on conformational stability. The most incisive results in this regard involved $a \rightarrow \beta$ replacements within the lone $a$-helix of the GB1 tertiary structure. Each of the helixmodified GB1 variants contained four $\alpha \rightarrow \beta$ replacements, which resulted in significant destabilization of the native fold. ${ }^{19}$ Our study complements the GB1 work in that we have employed a different tertiary structure, VHP, and we evaluate single $a \rightarrow \beta$ replacements.

VHP is one of the smallest poly-a-peptides known to form a discrete tertiary structure without internal crosslinks resulting from disulfide formation or metal ion chelation, either of which could convolute the thermodynamic impact of backbone modifications on a tertiary structure. ${ }^{1-3}$ Our experimental design focuses on single $a \rightarrow \beta$ replacements at four solventexposed sites within helical segments of VHP (Figure 1). At each site, both a $\beta^{3}$ and a cyclic $\beta$ residue were evaluated. Circular dichroism (CD) was used to determine the impact of each $a \rightarrow \beta$ replacement on the extent of $a$-helix formation, which provides an indirect indication of tertiary structure formation; variable-temperature CD data allow us to assess the effects of 
each $\alpha \rightarrow \beta$ replacement on tertiary structural stability. For each of the four native $a$ residues that were replaced with the $\beta^{3}$ homologue (identical side chain), the single-site backbone modification caused a decline in tertiary structure stability. At some but not all of the substitution sites, use of a conformationally constrained $\beta$ residue led to a recovery of tertiary structural stability. Quasiracemic crystallography enabled high-resolution structural analysis of several VHP variants and facilitated comparisons between local conformations of $\beta$ residues and the a residues they replaced. Overall, these findings contribute to a small but fundamental knowledge-base that should inform rational design of functional $\alpha / \beta$ analogues of natural poly-a-peptides.

\section{Results and Discussion}

\section{Design of Substitution Positions}

The first round of replacements in VHP involved $\beta^{3}$-homoamino acid residues homologous to the original a residues (Figure 1); thus, Asn was replaced by $\beta^{3}$-hAsn, Trp by $\beta^{3}-h \operatorname{Trp}$, etc. In these replacements, the side chain found in the natural VHP domain is retained, but an extra methylene is inserted into the backbone. The second round of replacements involved cyclic $\beta$ residues. In these cases, the native amino acid side chains were not retained. For positions with uncharged side chains (Asn19, Trp23 and Gln26), the cyclopentane-based $\beta$ residue designated ACPC was used, while for the position with a basic side chain (Lys30), the pyrrolidine-based $\beta$ residue designated APC was used (Figure 1). All VHP analogues were prepared via standard Fmoc-based solid-phase synthesis. Previous work with peptides that adopt $a$-helical secondary structure has established that fivemembered ring constraint with trans stereochemistry predisposes the $\beta$ residue backbone to adopt an a-helix-like local conformation. ${ }^{4}$ Crystallographic data from Horne et al. show that the a-helix-like local conformation of the ACPC residue is manifested also in backbonemodified variants of the GB1 tertiary structure. ${ }^{19,20}$

\section{Circular Dichroism Spectra}

The impact of each $a \rightarrow \beta$ replacement on tertiary structural stability was assessed via variable-temperature circular dichroism $(\mathrm{CD})$ measurements made in $20 \mathrm{mM}$ sodium acetate (pH 5.0). VHP itself and each of the new variants displays a CD spectrum with two minima in the far-UV region, one near $\sim 223 \mathrm{~nm}$ and the other near $\sim 208 \mathrm{~nm}$, as expected for an ahelix-rich folding pattern (Figure 2). The intensities of the $\mathrm{CD}$ signatures are generally similar among these polypeptides, but it is noteworthy that the $\sim 208 \mathrm{~nm}$ minimum is a little more intense for every $\beta$-containing variant relative to VHP itself. Previous work has shown that $\alpha / \beta$-peptides that contain multiple substitutions throughout the sequence and adopt ahelix-like conformations display only one far-UV CD minimum, near $208 \mathrm{~nm}^{23}$

\section{Thermodynamic Stability}

Fitting the variation in CD intensity at $223 \mathrm{~nm}$ vs. temperature to a two-state model (folded vs. unfolded) allowed us to estimate a melting temperature $\left(T_{\mathrm{m}}\right)$ for each VHP variant (Figure 3, Table 1). For each of the four sites evaluated, replacing the original a residue with the $\beta^{3}$ homologue leads to a substantial decline in tertiary structure stability, with $\Delta T_{\mathrm{m}}=$ $\left[T_{\mathrm{m}}\right.$ (variant) $\left.-T_{\mathrm{m}}(\mathrm{VHP})\right]$ ranging from $-12^{\circ}$ to $-25^{\circ} \mathrm{C}$. This trend is consistent with the 
substantial declines in tertiary structure stability observed by Horne et al. for GB1 variants containing four $a \rightarrow \beta^{3}$ substitutions in the helical segment. ${ }^{19}$ Replacing a $\beta^{3}$ residue with a cyclic $\beta$ residue in the context of VHP led to divergent outcomes. For $\beta^{3}$ hTrp23 and $\beta^{3}$ hGln 26 , replacement with ACPC caused little change in $T_{\mathrm{m}}$. In contrast, $\beta^{3} \rightarrow$ cyclic $\beta$ was stabilizing at the other two positions: replacing $\beta^{3} \mathrm{hAsn} 19$ with ACPC increased $T_{\mathrm{m}}$ by $\sim 10^{\circ}$ $\mathrm{C}$, and replacing $\beta^{3} \mathrm{hLys} 30$ with APC increased $T_{\mathrm{m}}$ by $\sim 12^{\circ} \mathrm{C}$. The variant bearing APC at position 30 is indistinguishable from native VHP in terms of thermal stability. Cyclically constrained $\beta$ residues have been suggested to promote helical secondary structure through a preorganization of helical dihedral angles that lowers the entropic penalty of folding in isolated $\alpha$-helices, ${ }^{4}$ although this view has been questioned. ${ }^{21}$ Our results show $\beta^{3} \rightarrow$ cyclic $\beta$ replacement does not necessarily enhance conformational stability in the context of a tertiary structure, because considerable variation is observed among the four substitution sites in VHP. Chiu et al. demonstrated that norleucine (Nle) substitution for Lys24 had a stabilizing effect on the folded conformation of VHP, presumably because of the removal of an unfavorable His27-Lys24 side chain interaction (Coulomb repulsion) at $\mathrm{pH} 4.8$. Kubelka et al. showed that double Nle substitution at Lys24 and Lys29 provided additional stabilization relative to the single Lys24Nle substitution because the aliphatic Nle29 side chain could pack into the hydrophobic core. ${ }^{24}$ Therefore, local perturbations of residues proximal to $\beta$-substitution sites may explain, in part, the decrease in $T_{\mathrm{m}}$ that results from $\beta^{3}$ substitution for W23, Q26 or K30, and for cyclic $\beta$ residue substitution for W23 or Q26.

\section{Quasiracemic Crystallization}

We pursued quasiracemic crystallization in order to obtain structural insight on the impact of $a \rightarrow \beta$ replacements in VHP. Crystallization trials for each variant, which is composed mostly of L-a-amino acid residues, were conducted with a 1:1 mixture containing that variant and the enantiomer of VHP itself. Three considerations motivated this strategy. First, a racemic mixture is believed to be more susceptible to crystallization than is a single enantiomer, and this advantage may extend to quasiracemic mixtures. ${ }^{25-30}$ Second, all but one of the VHP variants are less stable than VHP itself, and diminished conformational stability seems likely to diminish crystallization propensity. We hypothesized that cocrystallization of the less robustly folded variants with the more stable D-VHP would mitigate this problem. Third, co-occurrence of a VHP variant and D-VHP in the same crystal lattice would provide the optimum basis for comparing the local conformation of the $\beta$ residue with the corresponding a residue in VHP itself.

We have previously used quasiracemic crystallography to compare a residues with a nonproteinogenic side chain in the context of folded VHP, ${ }^{31}$ and Kent et al. have applied quasiracemic crystallography to other types of side chain-modified polypeptides, ${ }^{32-34}$ but the present study represents the first examination of backbone modifications via quasiracemic crystallography.

We succeeded in optimizing crystal growth and cryoprotection conditions for the quasiracemates containing the VHP analogues harboring the $\beta^{3}$ hGln26, ACPC26, $\beta^{3}$ hLys30 or APC30 modification within a chain of L-a-amino acid residues paired with D-VHP. Each quasiracemate crystallized in space group $P 1$ with unique cell constants (Table S1-S4). In 
each of the four successful conditions quasiracemate crystals were grown from $5.8 \mathrm{mg} / \mathrm{mL}$ total peptide compared to the $50-100 \mathrm{mg} / \mathrm{mL}$ reported for L-VHP alone. ${ }^{2}$

\section{Crystal Structures}

Each structure was solved via molecular replacement, refined in space group $P 1$ and found to contain a distinct pseudo-inversion center that was detectable in the cumulative intensity distribution prior to structure solution (Supporting Information). The pseudo-inversion center combined with the primitive triclinic lattice indicates a pseudo- $P \overline{1}$ space group, which is consistent with the hypothesis of Wukovitz and Yeates that $P \overline{1}$ should be the most prevalent space group among truly racemic protein crystals. ${ }^{35}$ Among the four quasiracemates, K30APC contains only four peptide chains in the unit cell and exhibits the closest approximation to true inversion symmetry as evidenced by the RMSD between pairs of chains related by pseudo-inversion symmetry (Table 2). In addition, we employed a framework developed for small molecules to quantify the impact deviations of atomic coordinates from centrosymmetric positions would have on the distribution of normalized structure factor amplitudes, i.e., to quantify the 'degree of centrosymmetry' prior to structure solution. ${ }^{36}$ Our analysis indicated that among all the new structures, the K30APC quasiracemate distribution most closely mimicked that of a centrosymmetric structure (Supporting Information).

Local and global pseudo-inversion centers can be present in structures with $P \overline{1}$ symmetry and a high $Z$ number. ${ }^{37}$ Therefore, to confirm that global pseudo-inversion centers were correctly identified, putative centers were translated to the crystallographic origin and the resulting phase angles were plotted as normalized histograms for each quasiracemate structure (Figure 5). The observed bimodal distributions centered around $0^{\circ}$ and $180^{\circ}$ are consistent with the centrosymmetric phase angle constraint and pseudo- $P \overline{1}$ centering. The K30APC quasiracemate structure exhibits the sharpest phase angle distribution which is consistent with the pseudo-inversion RMSD values and structure factor amplitude distribution pseudosymmetry metrics.

Intriguingly, three quasiracemate structures (those with the L-VHP variant containing $\beta^{3}$ hGln26, ACPC26 or $\beta^{3}$ hLys30) exhibit the same type of crystal packing observed in a previously reported $P \overline{1}$ VHP racemate (PDB: 3TRY). ${ }^{31}$ However, for each of these three quasiracemates, the unit cell contains twice the number of VHP chains (eight vs. four) and is approximately double the volume of the VHP racemate unit cell (Figure 4). Comparable unit cell expansion has been observed for small molecule quasiracemates relative to the corresponding racemate and is characterized by translational non-crystallographic symmetry. ${ }^{38-40}$

The enlarged unit cells in the three new quasiracemates relative to the true VHP racemate could represent pronounced cases of commensurate modulation, a phenomenon in which adjacent unit cells are regularly displaced relative to one another in a manner that disrupts the translational symmetry of the crystal lattice. ${ }^{41}$ Modulated structures can be viewed as being defined by a supercell, i.e., a unit cell that contains all of the smaller unit cells that comprise a full phase of the modulation function. For the three quasiracemates that include L-VHP variants containing $\beta^{3}$ hGln26, ACPC 26 or $\beta^{3}$ hLys30, deviations from true inversion 
symmetry arising from each backbone modification result in the combination of two clusters of four polypeptide molecules to form the supercell (Figure 4). We considered the possibility that the three crystals featured incommensurate, i.e., irrational repeats, rather than commensurate modulation. However, the stable refinement of each quasiracemate structure supports the hypothesis that each lattice is based on a supercell corresponding to a commensurately modulated sub-structure that mimics the crystal packing in the previously reported VHP racemate. We note that modulated macromolecular crystals have been only rarely described in the past. ${ }^{42,43}$

Slight perturbations from the local secondary structure of native VHP at the backbone modification site may have subtle but significant impacts on the global conformation of the polypeptide chain. This conformational disparity between the native and modified polypeptides is manifest as a deviation from true inversion symmetry. The most obvious example of this phenomenon is in the K30APC quasiracemate, where there are two distinct modalities of heterochiral packing between the C-terminal phenylalanine and the hydrophobic core of an adjacent chain (Figures S61-S62). In the three other quasiracemate structures these symmetry-disrupting interactions are less apparent and comprise primarily glancing patches of hydrophobic surface area.

A heterochiral, hydrophobic packing interaction that involves the loop segment N19 to W23 is present in each of the four quasiracemate structures (Figure 6). Disruption of this interaction may explain our inability to optimize crystal growth conditions for quasiracemates with L-VHP variants containing $\alpha \rightarrow \beta$ substitutions at N19 or W23. This hypothesis suggests that solution-phase native structure mimicry does not necessarily ensure quasiracemic crystal growth, because favorable packing contacts may be precluded by the point(s) of difference between the quasi-enantiomers. Lattice contacts that promote inversion or pseudo-inversion symmetry are crucial for racemic or quasiracemic crystal growth.

The quasiracemates with L-VHP variants containing $\beta^{3}$ hGln26, ACPC26, $\beta^{3} h L y s 30$ or APC30 exhibit mimicry of the canonical $\alpha$-helix hydrogen bonding pattern at the site of substitution (Figure 7); however, the "extra" backbone carbon atom present in each case results in multiple 14-atom $\mathrm{H}$-bond rings in place of the standard 13-atom $\mathrm{H}$-bond rings of the $a$-helix. The additional backbone bond in a $\beta$ residue relative to an a residue results in a slight buckling of the backbone to accommodate the $\beta$ residue without disruption of the helical H-bonds (Figure 8). The $\varphi$ and $\psi$ torsion angles of the $\beta$ residues, which correspond with the conventional $a$ residue angles, lie in the ranges $-129.8^{\circ}$ to $-106.6^{\circ}$ and $-117.8^{\circ}$ to $-105.2^{\circ}$ respectively (Table 3). An additional torsion angle $\theta$, which arises from the $\mathrm{Ca}-\mathrm{C} \beta$ bond within each $\beta$ residue, lies in the range $75.2^{\circ}$ to $83.6^{\circ}$. These values are consistent with previously reported structures that contain multiple $\beta$ residues in a-helix-like conformations. ${ }^{19,20}$

\section{Influence of quasiracemate lattice on tertiary structures of variants?}

One might wonder whether the co-assembly of D-VHP and a $\beta$-containing variant of L-VHP into a pseudosymmetric crystal lattice could induce a deviation from the naturally preferred tertiary structure of one member of the quasiracemate pair. Since our four structures of DVHP are very similar to one another and to the mirror image of the structure of L-VHP from 
a chiral crystal, we can dismiss the possibility of cocrystallization-induced distortion of DVHP in any of the quasiracemates. Two lines of evidence argue against such distortion in the $\beta$-containing variants, although this possibility cannot be entirely excluded, particularly in terms of small-scale changes. First, each variant displays a CD spectrum that is very similar to the CD spectrum of L-VHP; these data reflect the folding behavior of isolated polypeptides in solution. Second, the APC30 variant of L-VHP is comparable to L-VHP itself in terms of tertiary structure stability (Table 1), and it is not obvious why D-VHP would play a conformationally dominant role upon cocrystallization with the APC30 variant. Therefore, the similarity between the tertiary structures of L-VHP and the APC30 variant, and, by extension, the other $\beta$-containing variants, appears to reflect the intrinsic folding preferences of these variants.

\section{Conclusions}

Our results suggest that single-site replacement of a native $\alpha$-helical residue with its $\beta^{3}$ homologue is generally destablizing to the tertiary folding pattern of VHP, although a nativelike tertiary structure can be maintained despite the insertion of an 'extra' carbon atom into the polypeptide backbone. This type of structural mimicry has been well-established in previous studies involving multiple $\alpha \rightarrow \beta^{3}$ replacements in $\alpha$-helical peptides. ${ }^{44,45}$ The impact of $\alpha \rightarrow \beta$ substitution on the stability of a polypeptide's conformation however, has been evaluated directly in only one previous case, involving a discrete tertiary structure different from the one we employed. ${ }^{19}$ Prior studies with helical peptides have suggested that conformational stability can be recovered upon replacement of $\beta^{3}$ residues with cyclic $\beta$ analogues such as ACPC or APC, ${ }^{11,45-47}$ but in most such systems the link between cyclic $\beta$ residues and conformational stabilization has been indirect. Our data reveal that the effect of $\beta^{3} \rightarrow$ cyclic $\beta$ substitution varies as a function of position within the VHP sequence. At two sites, 19 and 30, this substitution increases stability, although only in the latter case is the stability of native VHP matched. At the other two sites, 23 and $26, \beta^{3} \rightarrow$ cyclic $\beta$ substitution has little impact on stability. No hypothesis to explain the divergent outcomes of $\beta^{3} \rightarrow$ cyclic $\beta$ substitution at positions 26 and 30 emerges from inspection of crystallographic data for the VHP variants. Previous comparisons in the GB1 framework, all of which involved multiple sites of $\beta^{3} \rightarrow$ cyclic $\beta$ substitution, are consistent with the trends we have observed for single substitutions in the VHP framework. ${ }^{19,20}$ Collectively, these studies of $\alpha \rightarrow \beta$ replacement in distinct tertiary contexts lay a foundation for the design of $\alpha / \beta$ tertiary structures intended to perform specific functions. ${ }^{17,21,22,46,16}$ In the future it will be interesting to examine the impact of $\beta$ residue substitutions in non-helical segments within discrete tertiary structures. Loops that connect $a$-helices and/or $\beta$-strands should be regions of particular interest because such loops are often involved in protein-protein interactions, and $\beta$ substitutions at these positions may exert larger effects on non-local contacts within crystal lattices than is observed for substitutions within a-helices.

\section{Supplementary Material}

Refer to Web version on PubMed Central for supplementary material. 


\section{Acknowledgments}

This work was supported in part by the NIH (R01GM061238 to SHG) and the NSF (MCB1518160 to KTF). DFK was supported in part by a Biotechnology Training Grant (T32 GM00839), and DEM was supported in part by a Biophysics Training Grant (T32 GM08293). Use of the Advanced Photon Source, a U.S. Department of Energy (DOE) Office of Science User Facility operated for the DOE Office of Science by Argonne National Laboratory under Contract No. DE-AC02-06CH11357. Use of the LS-CAT Sector 21 was supported by the Michigan Economic Development Corporation and the Michigan Technology Tri-Corridor (Grant 085P1000817). We are grateful to Dr. Zdzislaw Wawrzak of LS-CAT for his help with data collection, and we thank Dr. Ross Cheloha for his generous contribution of APC.

\section{ABBREVIATIONS}

$\begin{array}{ll}\text { VHP } & \text { Villin headpiece } \\ \text { IL-8 } & \text { Interleukin } 8 \\ \text { GLP-1 } & \text { Glucagon-like peptide } 1 \\ \text { GB1 } & \text { Protein G B1 domain } \\ \text { CD } & \text { Circular dichroism } \\ \text { ACPC } & \text { trans- }(1 S, 2 S) \text {-2-aminocyclopentyl-1-carboxylic acid } \\ \text { APC } & \text { trans- }(3 R, 4 S) \text {-4-aminopyrrolidine-3-carboxylic acid } \\ \text { vt-CD } & \text { Variable temperature circular dichroism } \\ \text { Nle } & \text { norleucine }\end{array}$

\section{References}

1. Žoldak G, Stigler J, Pelz B, Li H, Rief M. Proc Natl Acad Sci U S A. 2013; 110(45):18156-18161. [PubMed: 24145407]

2. Chiu TK, Kubelka J, Herbst-Irmer R, Eaton Wa, Hofrichter J, Davies DR. Proc Natl Acad Sci U S A. 2005; 102(21):7517-7522. [PubMed: 15894611]

3. McKnight CJ, Matsudaira PT, Kim PS. Nat Struct Biol. 1997; 4(3):180-184. [PubMed: 9164455]

4. Johnson LM, Gellman SH. Methods Enzymol. 2013; 523:407-429. [PubMed: 23422441]

5. Horne WS, Gellman SH. Acc Chem Res. 2008; 41(10):1399-1408. [PubMed: 18590282]

6. Goodman CM, Choi S, Shandler S, DeGrado WF. Nat Chem Biol. 2007; 3(5):252-262. [PubMed: 17438550]

7. Guichard G, Huc I. Chem Commun (Camb). 2011; 47(21):5933-5941. [PubMed: 21483969]

8. Aguilar M-I, Purcell AW, Devi R, Lew R, Rossjohn J, Smith aI, Perlmutter P. Org Biomol Chem. 2007; 5(18):2884-2890. [PubMed: 17728852]

9. Schievano E, Mammi S, Carretta E, Fiori N, Corich M, Bisello A, Rosenblatt M, Chorev M, Peggion E. Biopolymers. 2003; 70(4):534-547. [PubMed: 14648764]

10. Denton EV, Craig CJ, Pongratz RL, Appelbaum JS, Doerner AE, Narayanan A, Shulman GI, Cline GW, Schepartz A. Org Lett. 2013; 15(20):5318-5321. [PubMed: 24087900]

11. Boersma MD, Haase HS, Peterson-Kaufman KJ, Lee EF, Clarke OB, Colman PM, Smith BJ, Horne WS, Fairlie WD, Gellman SH. J Am Chem Soc. 2012; 134(1):315-323. [PubMed: 22040025]

12. Cheloha RW, Maeda A, Dean T, Gardella TJ, Gellman SH. Nat Biotechnol. 2014; 32(7):653-655. [PubMed: 24929976] 
13. Lengyel, Ga; Frank, RC.; Horne, WS. J Am Chem Soc. 2011; 133(12):4246-4249. [PubMed: 21370877]

14. Lengyel GA, Horne WS. J Am Chem Soc. 2012; 134:15906-15913. [PubMed: 22946450]

15. Hegedüs Z, Wéber E, Kriston-Pál É, Makra I, Czibula Á, Monostori É, Martinek Ta. J Am Chem Soc. 2013; 135(44):16578-16584. [PubMed: 24088182]

16. Arnold U, Hinderaker MP, Nilsson BL, Huck BR, Gellman SH, Raines RT. J Am Chem Soc. 2002; 124(29):8522-8523. [PubMed: 12121081]

17. David R, Günther R, Baumann L, Lühmann T, Seebach D, Hofmann HJ, Beck-Sickinger AG. J Am Chem Soc. 2008; 130(46):15311-15317. [PubMed: 18942784]

18. Peggion E, Mammi S, Schievano E, Silvestri L, Schiebler L, Bisello A, Rosenblatt M, Chorev M. Biochemistry. 2002; 41(25):8162-8175. [PubMed: 12069609]

19. Reinert ZE, Lengyel Ga, Horne WS. J Am Chem Soc. 2013; 135(34):12528-12531. [PubMed: 23937097]

20. Reinert ZE, Horne WS. Chem Sci. 2014; 5(8):3325-3330. [PubMed: 25071931]

21. Mayer C, Müller MM, Gellman SH, Hilvert D. Angew Chemie - Int Ed. 2014; 53(27):6978-6981.

22. Checco JW, Kreitler DF, Thomas NC, Belair DG, Rettko NJ, Murphy WL, Forest KT, Gellman SH. Proc Natl Acad Sci. 2015; 112(15):4552-4557. [PubMed: 25825775]

23. Horne WS, Price JL, Gellman SH. Proc Natl Acad Sci U S A. 2008; 105(27):9151-9156. [PubMed: 18587049]

24. Kubelka J, Chiu TK, Davies DR, Eaton WA, Hofrichter J. J Mol Biol. 2006; 359:546-553. [PubMed: 16643946]

25. Fredga A. Tetrahedron. 1960; 8:126-144.

26. Brock CP, Schweizer WB, Dunitz JD. J Am Chem Soc. 1991; 113(26):9811-9820.

27. Zawadzke LE, Berg JM. J Am Chem Soc. 1992; 114(10):4002-4003.

28. Brock CP, Dunitz JD. Chem Mater. 1994; 6(8):1118-1127.

29. Wheeler KA, Grove RC, Davis RE, Kassel WS. Angew Chemie Int Ed. 2008; 47(1):78-81.

30. Yeates TO, Kent SBH. Annu Rev Biophys. 2012; 41:41-61. [PubMed: 22443988]

31. Mortenson DE, Satyshur Ka, Guzei Ia, Forest KT, Gellman SH. J Am Chem Soc. 2012; 134(5): 2473-2476. [PubMed: 22280019]

32. Pentelute BL, Gates ZP, Dashnau JL, Vanderkooi JM, Kent SBH. J Am Chem Soc. 2008; 130(30): 9702-9707. [PubMed: 18598026]

33. Mandal K, Pentelute BL, Bang D, Gates ZP, Torbeev VY, Kent SBH. Angew Chemie - Int Ed. 2012; 51(6):1481-1486.

34. Okamoto R, Mandal K, Sawaya MR, Kajihara Y, Yeates TO, Kent SB. Angew Chem Int Ed Engl. 2014:5194-5198. [PubMed: 24692304]

35. Wukovitz SW, Yeates TO. Nat Struct Biol. 1995; 2(12):1062-1067. [PubMed: 8846217]

36. Srinivasan R, Swaminathan P. Curr Sci. 1975; 44(3):71-73.

37. Desiraju GR, Calabrese JC, Harlow RL. Acta Crystallogr Sect B Struct Sci. 1991; 341(2):77-86.

38. Kelley SP, Fábián L, Brock CP. Acta Crystallogr Sect B Struct Sci. 2011; 67(1):79-93.

39. Yurdakul A, Gurtner C, Lorenziriatsch A, Linden A, Guggisberg A, Hesse M. Helv Chim Acta. 1998; 81:1373-1392.

40. Lineberry AM, Benjamin ET, Davis RE, Kassel WS, Wheeler Ka. Cryst Growth Des. 2008; 8(2): 612-619.

41. Janssen, T.; Janner, A.; Looijenga-Vos, A.; de Wolff, PM. International Tables for Crystallography. Wilson, AJC.; Prince, E., editors. Vol. C. Kluwer Academic Publishers; Dordrecht, Boston, London: 2006. p. 907-955.

42. Read RJ, Adams PD, McCoy AJ. Acta Crystallogr D Biol Crystallogr. 2013; 69(Pt 2):176-183. [PubMed: 23385454]

43. Lovelace JJ, Murphy CR, Daniels L, Narayan K, Schutt CE, Lindberg U, Svensson C, Borgstahl GEO. J Appl Crystallogr. 2008; 41(3):600-605.

44. Horne WS, Price JL, Keck JL, Gellman SH. J Am Chem Soc. 2007; 129(14):4178-4180.

[PubMed: 17362016] 
45. Horne WS, Johnson LM, Ketas TJ, Klasse PJ, Lu M, Moore JP, Gellman SH. Proc Natl Acad Sci U S A. 2009; 106(35):14751-14756. [PubMed: 19706443]

46. Haase HS, Peterson-Kaufman KJ, Levengood SKL, Checco JW, Murphy WL, Gellman SH. J Am Chem Soc. 2012; 134(18):1-24. [PubMed: 22235988]

47. Peterson-Kaufman KJ, Haase HS, Boersma MD, Lee EF, Fairlie WD, Gellman SH. ACS Chem Biol. 2015; 10:1667-1675. [PubMed: 25946900] 
A)

C)
B)

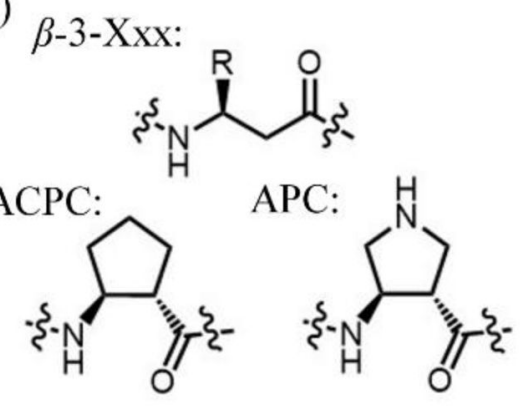

\section{LSDEDFKAVFGMTRSAFANLPLWKQQHIKKEKGLF}

\section{Figure 1.}

A) A previously reported crystal structure of the Villin headpiece subdomain (VHP; PDB entry $1 \mathrm{YRF}$ ), with positions at which $\beta$ residues were substituted in this study shown in blue. B) Structures of a generic $\beta^{3}$-homoamino acid residue, the trans-(1S,2S)-2aminocyclopentyl-1-carboxylic acid (ACPC) residue, and the trans-(3R,4S)-4aminopyrrolidine-3-carboxylic acid (APC) residue. C) $\beta^{3}$-homoaminoacid substitutions were made individually for native residue Asn19, Trp23, Gln26, or Lys30, the positions of which are shown in blue within the native sequence; in addition, ACPC substitutions were made individually for native residue Asn19, Trp23, or Gln26, and APC was substituted for Lys30. 

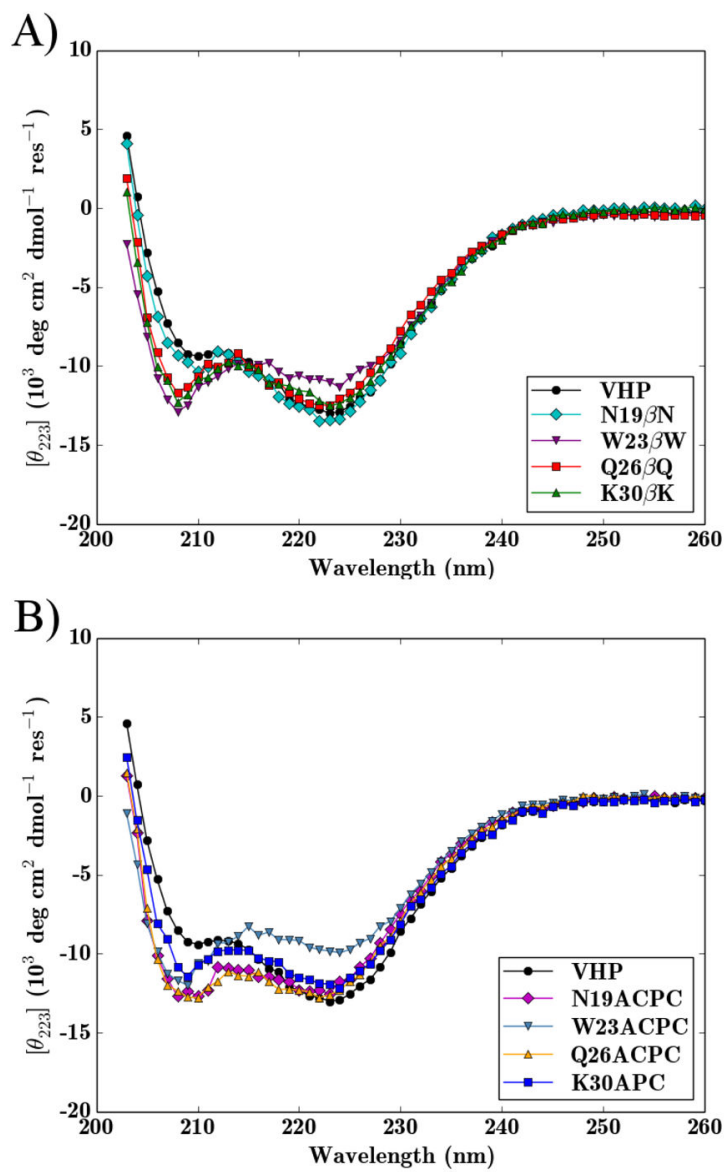

Figure 2.

Far-UV circular dichroism (CD) data for VHP derivatives containing A) single acyclic $\left(\beta^{3}\right)$ or B) cyclic $\beta$-amino acid substitutions. $\mathrm{CD}$ data were obtained in $20 \mathrm{mM}$ aqueous sodium acetate buffer, $\mathrm{pH} 5.0$, at $50 \mu \mathrm{M}$ peptide. 
A)

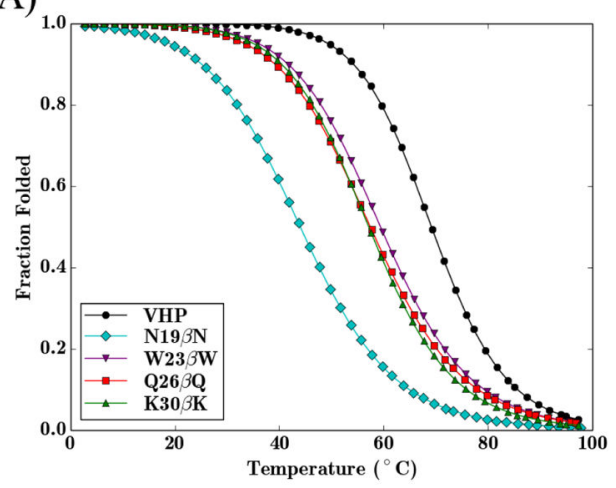

B)

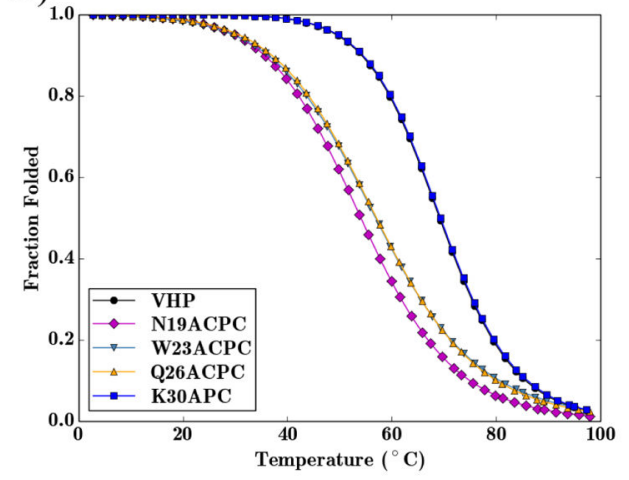

Figure 3.

Variable-temperature circular dichroism (vt-CD) measurements were performed by monitoring the ellipticity at $223 \mathrm{~nm}$ for VHP and variants containing either A) a single acyclic $\left(\beta^{3}\right)$ or $B$ ) a single cyclic $\beta$ residue substitution. Data were acquired in $20 \mathrm{mM}$ aqueous sodium acetate, $\mathrm{pH} 5.0$, at $50 \mu \mathrm{M}$ peptide. For each variant, model parameters ( $T_{\mathrm{m}}$, $\left.\Delta H_{\mathrm{m}}\right)$ and baselines were fit using non-linear regression analysis averaged over three independent measurements. Results are reported as fraction folded. See Supporting Information for vt-CD data plotted in terms of mean residue ellipticity. 
A)

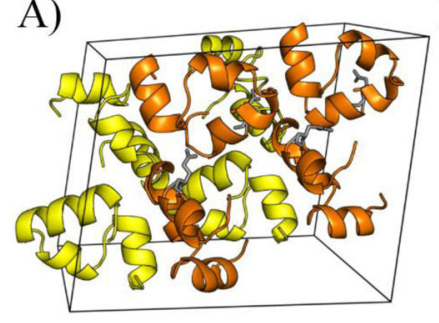

C)

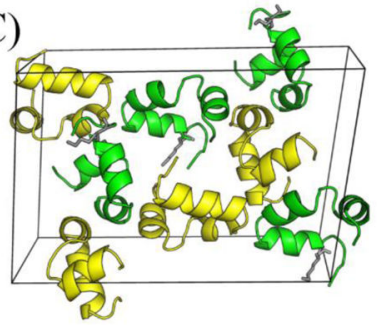

B)

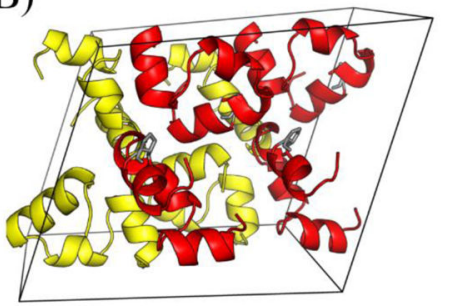

D)

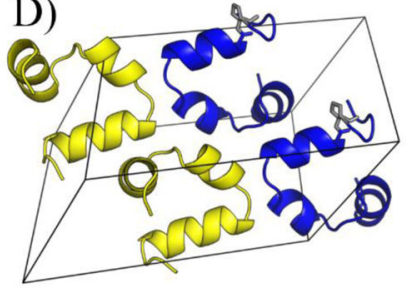

E)

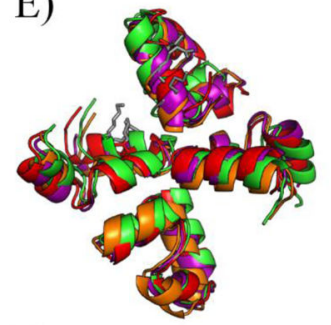

F)

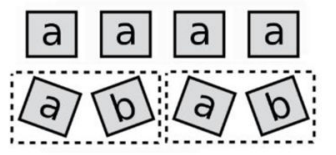

Figure 4.

Quasiracemate unit cell for A) Q26 $\beta$ Q (orange), B) Q26ACPC (red), C) K30 $\beta$ K (green), and D) K30APC (blue). In each unit cell D-VHP is shown in yellow. E) Quasiracemates Q26ßQ (orange), Q26ACPC (red) and K30ßK (green) exhibit packing patterns very similar to that of a previously reported VHP racemate (purple; PDB entry 3TRY), but each quasiracemate has twice the number of chains per unit cell relative to racemic VHP. F) A pictorial representation of commensurate modulation illustrating how modulation in one dimension results in an enlarged unit cell. 

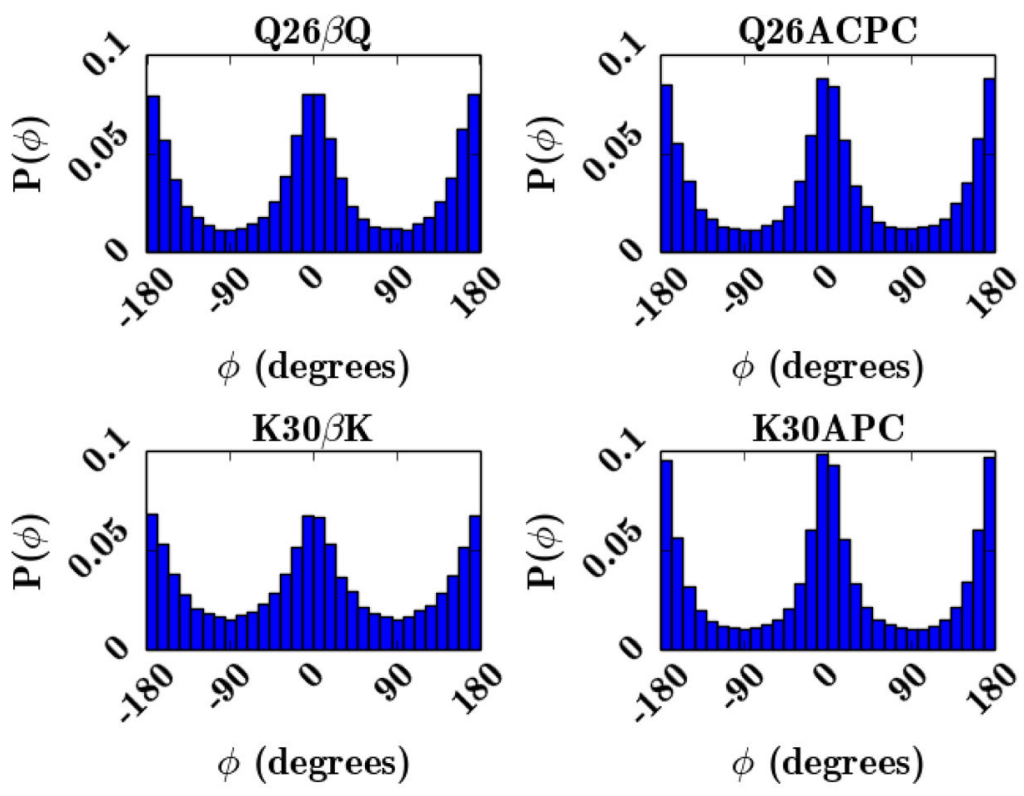

Figure 5.

Phase angle distributions for each of the four quasiracemate models. Phase angles were binned $(\mathrm{N}=30)$ as normalized histograms at the resolutions reported in Tables $\mathrm{S} 1-\mathrm{S} 4$. 
A)

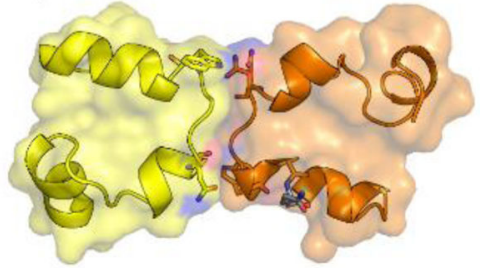

C)

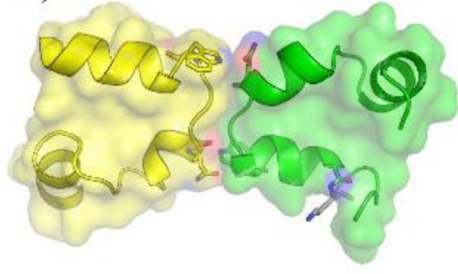

B)

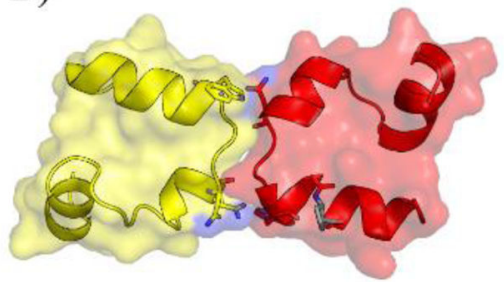

D)

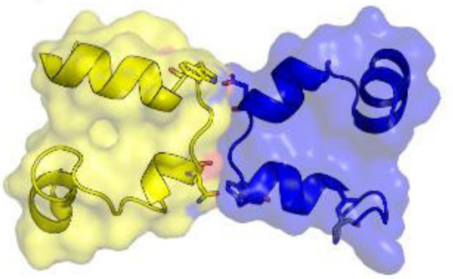

Figure 6.

A heterochiral packing contact between residues Asn19 and Trp23 was observed in each quasiracemate structure reported here. A) Q26 $\beta$ Q (orange), B) Q26ACPC (red), C) K30 $3 \mathrm{~K}$ (green), and D) K30APC (blue). D-VHP is shown in yellow. The side chains of Asn and Trp residues are shown in each case. 
A)

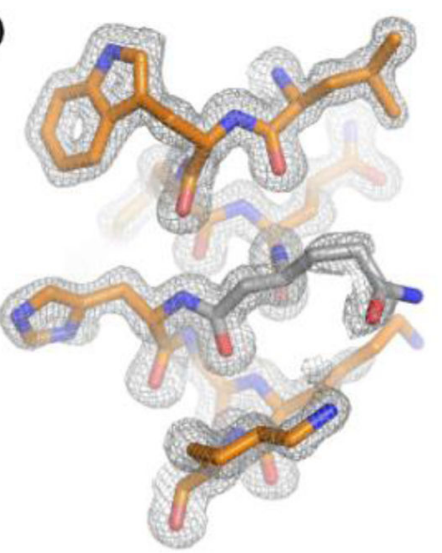

C)

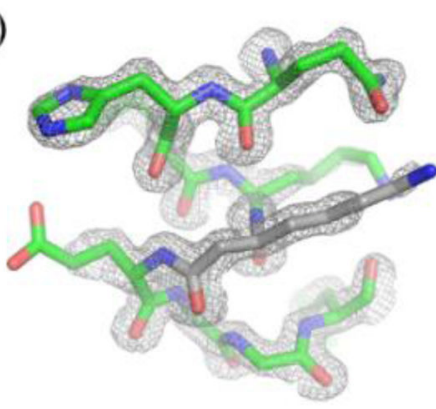

B)

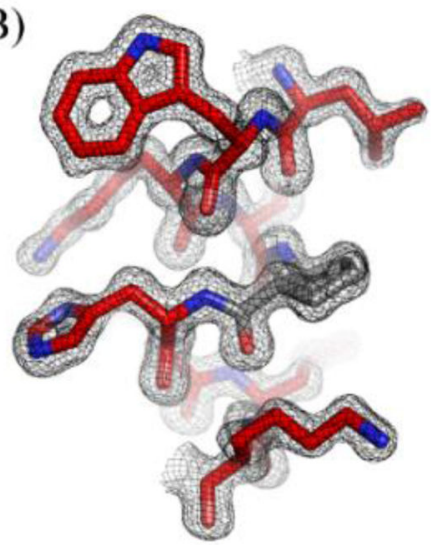

D)

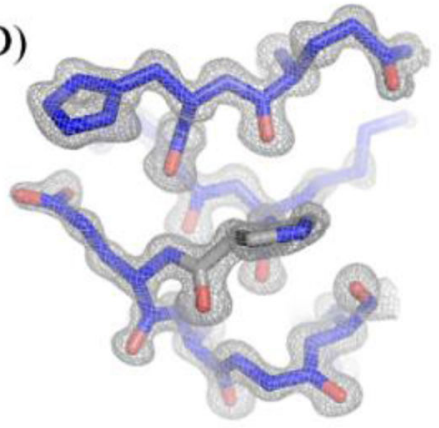

Figure 7.

$2 \mathrm{mF}_{\mathrm{o}}-\mathrm{DF}_{\mathrm{c}}$ weighted electron density maps contoured at $1.5 \sigma$ for A) Q26 $\beta \mathrm{Q}$ (orange) and $\mathrm{B}$ ) Q26ACPC (red) between residues Leu22 and Lys30; comparable images are shown for C) K30 $\beta K$ (green) and D) K30APC (blue) between Gln26 and Leu34. $\beta$ residues are shown in gray. 

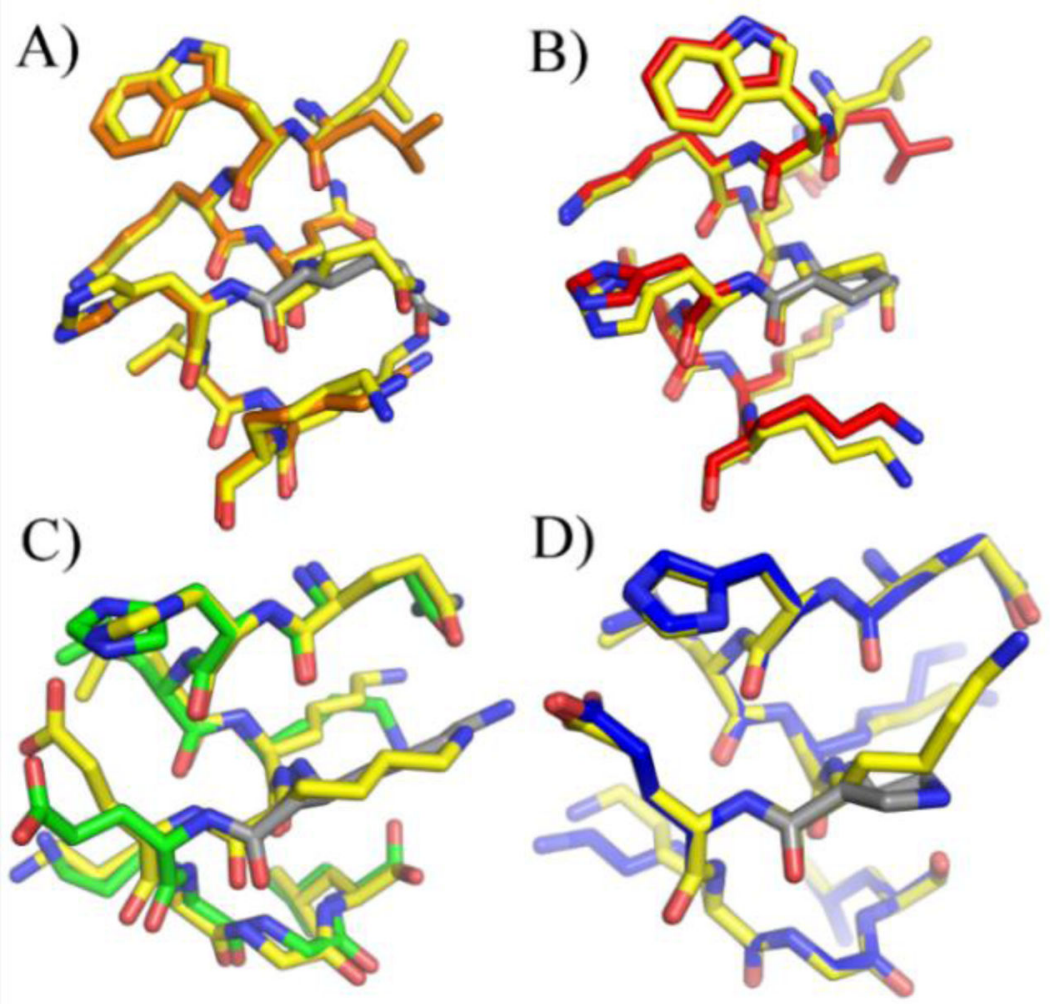

Figure 8.

Overlay of inverted D-VHP (yellow) with the corresponding pseudo-inversion symmetry mate for A) Q26ßQ (orange) and B) Q26ACPC (red) between residues Leu22 and Lys30; comparable overlays for C) K30ßK (green) and D) K30APC (blue) between Gln26 and Leu34. $\beta$ residues are shown in gray. 
A)

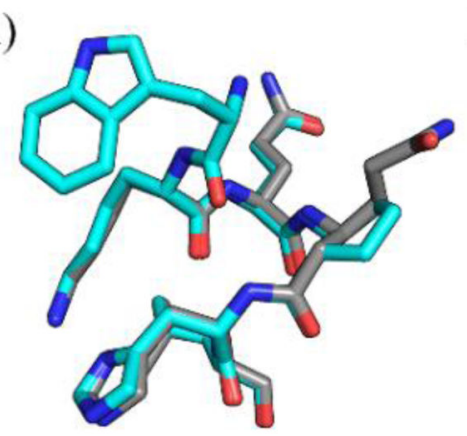

B)

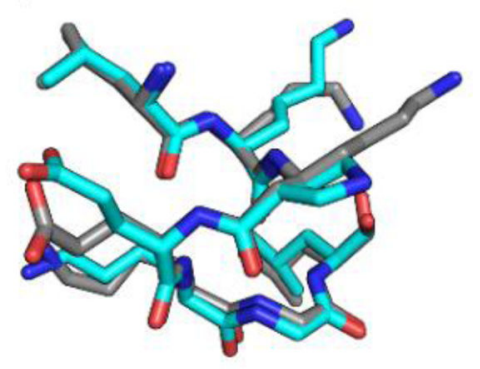

Figure 9.

Cyclic $\beta$ residues (cyan) compared with acyclic $\beta^{3}$ residues (gray) by overlaying backbone atoms (C, $\mathrm{Ca}, \mathrm{N}, \mathrm{O})$ for A) ACPC26 vs. $\beta 3 \mathrm{~h}-\mathrm{Gln} 26$ and B) APC30 vs. $\beta 3 \mathrm{~h}-\mathrm{Lys} 30$. 


\section{Table 1}

CD-derived folding for native VHP and $\beta$-substituted variants. ${ }^{a}$

\begin{tabular}{ccccc}
\hline Variant & $\boldsymbol{T}_{\mathbf{m}}\left({ }^{\circ} \mathbf{C}\right)$ & $\Delta \boldsymbol{H}_{\mathbf{m}}(\mathbf{k c a l} / \mathbf{m o l})$ & $\Delta \boldsymbol{T}_{\mathbf{m}}\left({ }^{\circ} \mathbf{C}\right)$ & $\Delta \Delta \boldsymbol{H}_{\mathbf{m}}(\mathbf{k c a l} / \mathbf{m o l})$ \\
\hline VHP & $69.1( \pm 0.4)$ & $32.8( \pm 1.2)$ & - & - \\
$\mathrm{N} 19 \beta^{3} \mathrm{~N}$ & $44.2( \pm 1.7)$ & $22.3( \pm 2.8)$ & $-25.0( \pm 2.1)$ & $-10.5( \pm 4.0)$ \\
$\mathrm{W} 23 \beta^{3} \mathrm{~W}$ & $59.4( \pm 0.7)$ & $25.9( \pm 0.6)$ & $-9.7( \pm 1.1)$ & $-6.9( \pm 1.8)$ \\
$\mathrm{Q} 26 \beta^{3} \mathrm{Q}$ & $57.4( \pm 0.9)$ & $24.8( \pm 1.5)$ & $-11.7( \pm 1.3)$ & $-8.1( \pm 2.7)$ \\
$\mathrm{K} 30 \beta^{3} \mathrm{~K}$ & $57.2( \pm 1.7)$ & $27.2( \pm 1.3)$ & $-11.9( \pm 2.1)$ & $-5.6( \pm 1.6)$ \\
$\mathrm{N} 19 \mathrm{ACPC}$ & $54.0( \pm 1.1)$ & $24.0( \pm 0.6)$ & $-15.1( \pm 1.5)$ & $-8.8( \pm 1.8)$ \\
$\mathrm{W} 23 \mathrm{ACPC}$ & $56.9( \pm 0.4)$ & $22.0( \pm 3.9)$ & $-12.2( \pm 0.8)$ & $-10.8( \pm 1.6)$ \\
$\mathrm{Q} 26 \mathrm{ACPC}$ & $57.1( \pm 1.0)$ & $22.1( \pm 0.5)$ & $-12.1( \pm 1.4)$ & $-10.7( \pm 1.7)$ \\
$\mathrm{K} 30 \mathrm{APC}$ & $69.4( \pm 1.2)$ & $33.0( \pm 2.7)$ & $0.3( \pm 1.6)$ & $-0.1( \pm 3.9)$ \\
\hline
\end{tabular}

${ }^{a}$ The two-state folding parameters $T_{\mathrm{m}}$ and $\Delta H_{\mathrm{m}}$ were derived by assuming that $\Delta C_{\mathrm{p}}=0 . \Delta T_{\mathrm{m}}$ and $\Delta \Delta H_{\mathrm{m}}$ are defined as the value for native VHP minus the value for the variant with the indicated $\beta$-substitution. The standard deviation for each reported parameter was determined from three separate measurements and fitting sessions. 


\section{Table 2}

Mean intra-crystal backbone atom RMSD $(\AA)$ values for pseudo-inversion related pairs of chains ${ }^{a}$

\begin{tabular}{cccc}
\hline Variant & Pseudo-inversion & All possible L/D & D/3TRY \\
\hline $\mathrm{Q} 26 \beta^{3} \mathrm{Q}$ & $0.10^{b}(0.02)$ & $0.28(0.12)$ & $0.34(0.05)$ \\
$\mathrm{Q} 26 \mathrm{ACPC}$ & $0.16^{b}(0.12)$ & $0.40(0.19)$ & $0.41(0.13)$ \\
$\mathrm{K} 30 \beta^{3} \mathrm{~K}$ & $0.15^{b}(0.04)$ & $0.41(0.22)$ & $0.39(0.11)$ \\
$\mathrm{K} 30 \mathrm{APC}$ & $0.070^{b, c}$ & $0.42(0.41)$ & $0.53^{c}$ \\
\hline
\end{tabular}

a Mean RMSD values vary from 0.07 to $0.16 \AA$ for pseudo-inversion related pairs of chains (first column) and from 0.28 to $0.42 \AA$ for all possible L/D chain pairs within a crystal (second column). Values were calculated using backbone atoms $(\mathrm{C}, \mathrm{Ca}, \mathrm{N}, \mathrm{O})$; the 'extra' $\beta$ residue $\mathrm{C}$ atom of each $\beta$ residue was excluded. In addition to these intra-crystal comparisons (first two columns), we compared the D-VHP chains from each crystal with the D-chain in the previously reported VHP racemate structure (third column) (PDB: 3TRY). One standard deviation is reported in parentheses.

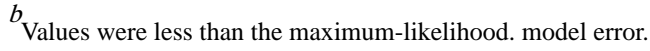

$c^{c}$ The two values were equivalent, thus no standard deviation is reported. 
Table 3

Torsion angles for $\beta$ residues in quasiracemic crystal structures. ${ }^{a}$

\begin{tabular}{|c|c|c|c|}
\hline Variant & $\varphi\left({ }^{\circ}\right)$ & $\theta\left({ }^{\circ}\right)$ & $\psi\left({ }^{\circ}\right)$ \\
\hline $\mathrm{Q} 26 \beta^{3} \mathrm{Q}$ & $-110.2,-106.7$ & $75.2,82.3$ & $-117.8,-116.4$ \\
\hline Q26ACPC & $-111.7,-105.7$ & $79.1,83.6$ & $-116.6,-112.8$ \\
\hline $\mathrm{K} 30 \beta^{3} \mathrm{~K}$ & $-129.8,-110.6$ & $75.9,82.4$ & $-107.2,-105.2$ \\
\hline K30APC & $-119.1,-106.6$ & $77.4,81.9$ & $-112.0,-106.6$ \\
\hline
\end{tabular}

${ }^{a}$ Torsion angles were tabulated for each crystallographically independent $\beta$ residue and are reported as [min, max] ranges. Conventional nomenclature was used for $\varphi$ and $\psi$ torsion angles; however these values differ significantly from that of a residues in a standard a-helix ( $\varphi=$ $-57.8, \psi=-47.0$ ) because of the extra $\mathrm{C}$ atom in each $\beta$ residue. This extra backbone atom accounts also for the additional torsion angle, $\theta$. 